\title{
CORRECTION
}

\section{Correction to: Do close-call games attract more fans?}

\author{
Sooyoung Sul ${ }^{1}[$
}

Published online: 5 April 2019

(c) Springer Nature B.V. 2019

\section{Correction to: \\ Journal of Inclusion Phenomena and Macrocyclic Chemistry \\ https://doi.org/10.1007/s10847-019-00893-y}

In the original publication of the article, the department information of the author was published incorrectly. It has been updated in this correction.

Publisher's Note Springer Nature remains neutral with regard to jurisdictional claims in published maps and institutional affiliations.

The original article can be found online at https://doi.org/10.1007/ s10847-019-00893-y.

Sooyoung Sul

sooyoung815@hanmail.net

1 College of Physical Education, Kyonggi University,

154-42, Gwanggyosan-ro, Yeongtong-gu, Suwon-si,

Gyeonggi-do 16227, South Korea 